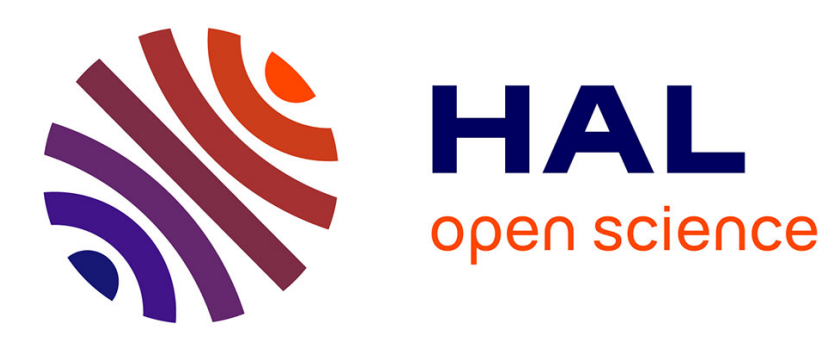

\title{
Ernest Renan et le projet nationaliste de Mário de Andrade \\ Rita Olivieri-Godet
}

\section{To cite this version:}

Rita Olivieri-Godet. Ernest Renan et le projet nationaliste de Mário de Andrade. Ernest Renan et le Brésil. Actes du colloque organisé par l'ERIMIT - Université de Rennes II. Octobre 2005, Oct 2005, RENNES, France. pp.115-133, 10.3406/renan.2009.1586 . halshs-02872481

\section{HAL Id: halshs-02872481 https://shs.hal.science/halshs-02872481}

Submitted on 17 Jun 2020

HAL is a multi-disciplinary open access archive for the deposit and dissemination of scientific research documents, whether they are published or not. The documents may come from teaching and research institutions in France or abroad, or from public or private research centers.
L'archive ouverte pluridisciplinaire HAL, est destinée au dépôt et à la diffusion de documents scientifiques de niveau recherche, publiés ou non, émanant des établissements d'enseignement et de recherche français ou étrangers, des laboratoires publics ou privés. 


\section{Ernest Renan et le projet nationaliste de Mário de Andrade} Rita Olivieri-Godet

\section{Citer ce document / Cite this document :}

Olivieri-Godet Rita. Ernest Renan et le projet nationaliste de Mário de Andrade. In: Études Renaniennes, №111, janvier 2009. Ernest Renan et le Brésil. Actes du colloque organisé par I'ERIMIT - Université de Rennes II. Octobre 2005. pp. 115-133; doi : https://doi.org/10.3406/renan.2009.1586

https://www.persee.fr/doc/renan_0046-2659_2009_num_111_1_1586

Fichier pdf généré le 09/05/2020 


\section{ERnest RENAN ET LE PROJET NATIONALISTE de Mário de ANDrade}

Le projet nationaliste de Mário de Andrade, tel qu’il se présente dans les premières années de la phase héroïque du Modernisme brésilien ${ }^{1}$, peut se définir à partir des idées et des principes philosophiques qui ont marqué le début du XXe siècle: l'homme universel, la libre volonté de l'individu, le caractère culturel de la nation. À ces principes, il faut ajouter la croyance dans une psychologie des peuples et les idées esthétiques modernes diffusées notamment par la revue Esprit Nouveau et par les œuvres de poètes tels que Whitman, Verhaeren ${ }^{2}$, Apollinaire ${ }^{3}$, Jules Romains ${ }^{4}$. Les œuvres de ces chantres de l'universel nourrissent la réflexion de Mário de Andrade et lui inspirent une certaine façon de concevoir le rapport de la poésie à l'univers. C'est dans un contexte de superposition d'influences, où les transferts culturels donnent souvent des produits différents, que les idées de Mário de Andrade ont mûri.

Le rapprochement et l'analyse des convergences entre les textes "Qu'est-ce qu'une nation?" de l'écrivain et philosophe français

${ }^{1}$ Sur le Modernisme brésilien voir Godet, Rita et Boudoy, Maryvonne (sous la direction de), Le Modernisme brésilien, série Travaux et Documents, $\mathrm{n}^{\circ} 10$, Saint-Denis, université Paris 8, 2000.

${ }^{2}$ En ce qui concerne les rapports entre Émile Verhaeren et Mário de Andrade, je renvoie à deux de nos articles : Rita Olivieri-Godet, "L’espace poétique de la ville chez Émile Verhaeren et Mário de Andrade ", in : Quint, Anne-Marie (sous la direction de), La ville exaltation et distanciation, Paris, Presses de la Sorbonne Nouvelle, 1997, p. 5782; Rita Olivieri-Godet, "La répercussion de l'œuvre de Verhaeren dans la littérature brésilienne ", Textyles : revue des lettres belges de langue française, $\mathrm{n}^{\circ}$ 11, Bruxelles, 1995, p. 163-170.

${ }^{3}$ Lecteur et admirateur d'Apollinaire, Mário de Andrade cite à plusieurs reprises, l'auteur des célèbres vers de "Vendémiaire" : "Écoutez-moi je suis le gosier de Paris/Et je boirai encore s'il me plaît l'univers/Écoutez mes chants d'universelle ivrognerie."

${ }^{4}$ Telê Porto Ancona Lopez, Mário de Andrade : ramais e caminho, São Paulo, Duas Cidades, 1972, p. 24 : "Pela profissao de fé do unanimista francês (Jules Romains), no "espoir de la vie unanime", Mário percebe a possibilidade de multiplicação do ser em vivências, buscando um todo futuro de integração universal e plenitude. " 
Ernest Renan (1823-1892) et "Noção de Pátria' " de l'écrivain moderniste brésilien Mário de Andrade (1893-1945) vont nous permettre de préciser les éléments qui sont communs à leurs réflexions sur le concept de nation, en soulignant les points de la pensée de Renan qui ont plus particulièrement nourri la réflexion du moderniste brésilien. Un constat initial s'impose : la formation chrétienne des deux écrivains qui fait que leur pensée évolue vers un horizon éthique ${ }^{2}$. Cette éthique humaniste et chrétienne est perceptible dans les deux textes qui, par ailleurs, n'ont pas le même poids : en une vingtaine de pages, Renan étale ses arguments de façon détaillée pour exposer son idée de nation; en seulement deux colonnes, écrites pour un petit journal de la Marine, Mário de Andrade expose brièvement son idée de patrie. C'est la raison pour laquelle nous aurons recours également à quelques extraits de son œuvre critique et poétique pour mettre en évidence les éléments ayant trait à la notion de nation que le Brésilien partage avec le philosophe français.

L'importance des auteurs français dans la formation de la pensée de Mário de Andrade a déjà fait l'objet de plusieurs études. Dans un travail consacré à l'évolution idéologique de Mário de Andrade, Telê Porto Ancona Lopez commente le concept de patrie que l'écrivain développe dans son article " Noção de pátria " ${ }^{3}$, sans établir de rapprochement avec le texte de Renan. Une étude de Nites Therezinha Feres sur les auteurs français lus par Mário de Andrade, présente une sélection des commentaires faits par l'auteur en marge de certains ouvrages, mais aucune référence n'est faite à Ernest Renan.

\footnotetext{
${ }^{1}$ Mário de Andrade, " Noção de Pátria ". O Fanal, Sant'Anna (?), 7 set. 1922. Album de Recortes M. de A. (R. 35) - IEB-USP (Instituto de Estudos Brasileiros - universidade de São Paulo). Le texte est reproduit en annexe avec l'orthographe de l'article original.

${ }^{2}$ Bien qu'ayant rompu avec l'Église catholique, Renan a toujours proclamé son respect pour les valeurs chrétiennes, qui représentent pour lui la catégorie de "l'idéal " dans un siècle matérialiste. Voir Ernest Renan, Souvenirs d'enfance et de jeunesse, chapitre VI.

${ }^{3}$ Telê Porto Ancona Lopez, op. cit., p. 44. Voir la note (33), p. 43 : «Andrade, Mário de - Noção de Pátria. O fanal, Sant'Anna (?), 7 set. 1922. "Recortes M. de A. - IEB-USP. "A indicação de periódico fornecida pelo escritor esclarece sobre $O$ Fanal: "jornaleco militar que se publica em Sant'Anna", dando a impressão de que provinha de bairro paulistano. O jornal não foi encontrado pela pesquisa. "
} 
Néanmoins, dès la préface de Paulicéia Desvairada (1922 1 ), le poète brésilien cite Ernest Renan à propos du caractère ambigu du langage. S'il est vrai que, dans son article " Noção de pátria " (1922), il n'y a pas de référence explicite au nom du philosophe français, nous allons démontrer que certaines des idées centrales développées par Renan dans son texte "Qu'est-ce qu'une nation?" (1882) ne s'en trouvent pas moins présentes.

Mário de Andrade lecteur de Renan. Parmi les livres qui figurent au fonds de la "Bibliothèque Mário de Andrade " de l'Institut d'Études Brésiliennes de l'université de São Paulo, nous trouvons Pages choisies de Renan ${ }^{2}$. Une note de la maison d'édition souligne son but de publier au Brésil les grands écrivains de la France contemporaine. Renan y apparaît aux côtés de Maurice Barrès (Les Diverses familles spirituelles de la France) et d'Albert Thibaudet (Histoire de la littérature française). Selon les éditeurs, la publication de ces Pages choisies a respecté " l'intégralité de la pensée de Renan " pour donner une vision globale de l'œuvre de ce "grand penseur": " depuis Patrice jusqu'à L'Origine du christianisme tout a été consulté. »

L'ouvrage s'organise autour de quatre parties: I Morale et philosophie; II Histoire et religion; III Littérature et critique; IV Souvenirs d'enfance et de jeunesse. Le texte "Qu'est-ce qu'une nation? ", suivi de l'information "Fragment d'une conférence ", appartient à la troisième partie. On ne trouve aucune observation de Mário de Andrade en marge de son exemplaire de l'ouvrage. D'après Telê Porto Ancona Lopez, ce n'est qu'en 1918 que commencent à apparaître ${ }^{3}$ lcs commentaircs cn marge des textes lus par Mário de Andrade ce qui peut nous conduire à penser, sans que toutefois nous puissions

\footnotetext{
'Sur ce recueil de poèmes voir Rita Olivieri-Godet, "L'identité nationale dans l'œuvre inaugurale du Modernisme brésilien: Paulicéia Desvairada de Mário de Andrade", Les langues néo-latines, Paris, $\mathrm{n}^{\circ} 297$, septembre 1996, p. 63-73.

${ }^{2}$ Pages choisies de Renan, Droits pour le Continent Américain : Améric $=$ Edit, Rio de Janeiro, Brasil. IEB, Bibliothèque Mário de Andrade (MA 848 R 393 p.).

${ }_{3}$ "Até 1917, não se pode contar com o auxílio de comentários marginais. Em 1918 começam a aparecer comentários críticos datados à margem de textos de livros. Até 1917, suas anotaçôes são apenas traços à margem, trechos sublinhados ou páginas citadas no anterosto. "Telê Porto Ancona Lopez, op. cit., p. 23.
} 
l'affirmer, que l'écrivain brésilien a peut-être pris connaissance de ce texte avant cette date.

En lisant Renan, on comprend mieux l'idée de l'homme universel et son rapport avec le concept de nation, tels qu'on les retrouve chez Mário de Andrade. Dans "Qu'est-ce qu'une nation? ", le philosophe français affirme son attachement aux valeurs des Lumières, sa croyance à l'homme en tant qu' être libre, moral et universel. Il y a un effort pour construire une conception d'un nationalisme humanitaire, un nationalisme qui s'éloigne du patriotisme tel que Todorov l'entend : "de la préférence pour les siens au détriment des autres ${ }^{1}$."

Cette considération exclusive de la langue a, comme l'attention trop forte donnée à la race, ses dangers, ses inconvénients. Quand on y met de l'exagération, on se renferme dans une culture déterminée, tenue pour nationale; on se limite, on se claquemure. On quitte le grand air qu'on respire dans le vaste champ de l'humanité pour s'enfermer dans des conventicules de compatriotes. Rien de plus mauvais pour l'esprit; rien de plus fâcheux pour la civilisation. N'abandonnons pas ce principe fondamental, que l'homme est un être raisonnable et moral, avant d'être parqué dans telle ou telle langue, avant d'être un membre de telle ou telle race, un adhérent de telle ou telle culture. Avant la culture française, la culture allemande, la culture italienne, il y a la culture humaine ${ }^{2}$.

Le nationalisme de Renan, comme le montre bien Tzvetan Todorov, "consiste à affirmer qu'on appartient à une nation par le seul effort de sa libre volonté ${ }^{3}$ ». Ni la race, ni la langue, ni la religion, ni la communauté des intérêts, ni les frontières ne sont suffisantes pour fonder une nation. Il s'agit donc d'une vision qui prend ses distances vis-à-vis du déterminisme positiviste et qui souligne les dangers d'une telle perspective: "L'étude de la race est capitale pour le savant qui s'occupe de l'histoire de l'humanité. Elle n'a pas

${ }^{1}$ Tzvetan Todorov, Nous et les autres. La réflexion française sur la diversité humaine, Paris, Seuil, 1989, p. 301.

${ }^{2}$ Ernest Renan, Qu'est-ce qu'une nation? Et autres écrits politiques, éditions de l'Imprimerie Nationale, 1996, p. 237.

${ }^{3}$ Tzvetan Todorov, op. cit., p. 301. 
d'application en politique. "Il s'agit aussi d'une vision qui distingue la Nation de l'État.

Ainsi, pour Renan, une nation est " un principe spirituel ", une conscience morale, un héritage historique partagé (" un passé héroïque, des grands hommes, de la gloire ") et une volonté commune dans le présent. Todorov a souligné la contradiction d'une telle formulation: " Le critère politique (la libre volonté) échappe aux dangers du patriotisme : mais le critère culturel (le passé commun) est au contraire interprété de manière égocentrique. " Ainsi, commente Todorov, si Renan a évité de réduire le nationalisme au patriotisme, il ne distingue pas " le politique et le culturel et interprète le culturel de manière patriotique ${ }^{1}$ ". Si ces contradictions existent, elles nous permettent aussi de souligner les éléments positifs de sa conception de la nation comme, par exemple, l'idée de la primauté des intérêts de la communauté sur ceux de l'individu et son universalisme qui refuse de façon radicale l'étroitesse du patriotisme :

Par leurs facultés diverses, souvent opposées, les nations servent à l'œuvre commune de la civilisation, toutes apportent une note à ce grand concert de l'humanité, qui en somme, est la plus haute réalité idéale que nous atteignions. Isolées, elles ont leurs parties faibles ${ }^{2}$.

Certaines réflexions de Renan sur la formation des nations modernes sont toujours très actuelles. Il est réconfortant de lire, dans ce texte, le refus du concept de pureté raciale et la mise en avant de tout un processus de métissage qui est à l'origine de la constitution des nations modernes, à contre-courant des considérations ethnographiques qui prévalaient à cette époque. Il attire l'attention sur le danger d'enfermement que constituerait un droit primordial des races comme principe fondateur d'une nation :

La considération ethnographique n'a donc été pour rien dans la constitution des nations modernes. La France est celtique, ibérique, germanique. L'Allemagne est germanique, celtique, slave. L'Italie est le pays où l'ethnographie

\footnotetext{
${ }^{1}$ Tzvetan Todorov, op. cit., p. 306.

${ }^{2}$ Ernest Renan, op. cit., p. 242.
} 
est la plus embarrassée. Gaulois, Étrusques, Pélasges, Grecs, sans parler de bien d'autres éléments s'y croisent dans un indéchiffrable mélange. [...]

La vérité est qu'il n'y a pas de race pure et que faire reposer la politique sur l'analyse ethnographique, c'est la faire porter sur une chimère. Les plus nobles pays, l'Angleterre, la France, l'Italie, sont ceux où le sang est le plus mêlé ${ }^{~}$.

L'usage de l'expression " les plus nobles pays " révèle un certain regard marqué par l'ethnocentrisme européen, malgré le fait que la pensée de Renan sur la nation s'oriente vers un humanisme universaliste. Il est difficile de faire une synthèse cohérente d'un texte qui laisse entrevoir quelques contradictions d'une pensée à la fois ouverte à la philosophie des Lumières mais également formée par les recherches des anthropologues et linguistes $\mathrm{du} \mathrm{XIX}^{\mathrm{c}}$ siècle sur les races.

De telles contradictions et limites sont évidemment tributaires du cadre intellectuel particulier de la période au cours de laquelle cette pensée s'est forgée. Il est évident que la conception de l'histoire propre à Renan est loin de celle des historiens actuels, notamment de ceux qui se donnent pour tâche de "faire l'inventaire des archives du silence ${ }^{2}$ " dans le but de la démystifier et de la décoloniser. Néanmoins, il y a dans ce texte des affirmations courageuses qui rejoignent la réflexion actuelle sur le processus de formation des nations, comme celle qui constate la violence inhérente à ce processus. Renan souligne les conflits violents dans la formation des nations, mais par ailleurs, il affirme le besoin de les oublier pour que celles-ci puissent se consolider :

L'investigation historique, en effet, remet en lumière les faits de violence qui se sont passés à l'origine de toutes les formations politiques, même de celles dont les conséquences ont été les plus bienfaisantes. L'unité se fait toujours brutalement; la réunion de la France du Nord et de la France du Midi a été le résultat d'une extermination et d'une terreur continuée pendant près d'un siècle ${ }^{3}$.

\footnotetext{
${ }^{1}$ Ernest Renan, op. cit., p. 232.

${ }^{2}$ Jacques Le Goff, Histoire et mémoire, Paris, Gallimard, 1988, p. 203.

${ }^{3}$ Ernest Renan, op. cit., p. 227.
} 
Or l'essence d'une nation est que tous les individus aient beaucoup de choses en commun, et aussi que tous aient oublié bien des choses ${ }^{1}$.

Il ne faut pas toutefois négliger l'importance de la reconnaissance d'un fait capital - l'existence de la violence tant de fois dissimulée dans les versions officielles de l'histoire de la formation des nations - malgré une position qui accepte la nécessité d'oublier cette violence.

Les plus grands legs de la pensée de Renan à la réflexion actuelle sur la nation se trouvent, selon nous, dans son refus de la guerre, dans son respect des différences culturelles et dans son espoir qu'un vrai dialogue interculturel puisse s'engager pour atteindre une harmonie universelle. La reconnaissance de l'importance de la pluralité des cultures est une utopie moderne que Renan exprimait déjà en ces termes :

Par leurs facultés diverses, souvent opposées, les nations servent à l'œuvre commune de la civilisation; toutes apportent une note à ce grand concert de l'humanité, qui, en somme, est la plus haute réalité idéale que nous atteignions ${ }^{2}$.

Chez Mário de Andrade, on trouve le même refus de placer la nation au-dessus de l'humanité. Son œuvre témoigne d'un nationalisme ouvert à un humanisme universaliste et chrétien (universalisme qui sera plus tard remplacé par une vision internationaliste au fur et à mesure que l'écrivain se rapprochera d'une perspective marxiste) agrémenté d'un regard esthétique avant-gardiste qui s'ouvre vers la multiplicité complexe du monde moderne. Dans $A$ escrava que não é Isaura, Mário de Andrade souligne son appartenance à la culture universelle en affirmant que "la vie actuelle nous fait vivre simultanément toutes les terres de l'univers ", pour ajouter plus loin :

O homem contemporâneo é um ser multiplicado.

... tres raças se caldeiam na minha carne...

Tres?

Fui educado num colégio francês. Palpito de entusiasmo, de amor ante a renovação da arte musical italiana. Admito e estudo Uidobro e Unamuno. Os Estados Unidos me entu-

${ }^{1}$ Ernest Renan, op. cit., p. 228.

${ }^{2}$ Renan, "Qu'est-ce qu'une nation?", p. 905. (Cité par Todorov, op. cit. p. 308.) 
siasmam como se fossem pátria minha. Com a aventura de Gago Coutinho fui português. Fui russo durante o Congresso de Genova. Alemão no Congresso de Versalhes. Mas não votei em ninguém nas últimas eleiçōes brasileiras ${ }^{1}$.

Les productions culturelles nationales constituent la contribution spécifique que chaque nation apporte à la culture universelle. Ainsi, l'œuvre de Mário de Andrade se construit à travers une formulation dialectique de la problématique de l'identité nationale. La nation est envisagée comme une unité dans la diversité. La connaissance et l'expression des cultures spécifiques sont des moyens de contribuer à la culture universelle. Pour Mário de Andrade, son désir d'élaborer une littérature révélatrice d'un "caractère national brésilien " n'exclut pas le dialogue avec les éléments étrangers : les caractéristiques sociales, esthétiques et morales de la spécificité brésilienne font partie du contexte universel. Ces idées se trouvent à la base du nationalisme critique et esthétique de l'auteur moderniste. La rupture avec la dépendance culturelle se fait par une recherche systématique des éléments qui constituent le "caractère national " - idée que Mário de Andrade développe en s'inspirant de la psychologie des peuples. En même temps, la connaissance approfondie de la réalité brésilienne est une voie qui conduit à l'universel.

Dès 1922, dans son article "Noção de Pátria " qu’il écrit pour un petit journal militaire $O$ Fanal, en commémoration du centenaire de l'Indépendance du Brésil, le concept de patrie s'ouvre vers une solution universaliste, comme le signale Telê Porto Ancona Lopez. La patrie est caractérisée comme le futur département indépendant des états uni-

${ }^{1}$ Mário de Andrade, A escrava que não é Isaura in Obra Imatura, São Paulo, Martins, 1980, p. 266.

"L'homme d'aujourd'hui est un être en constante multiplication.

...trois races mijotent dans ma chair...

Trois?

J'ai été éduqué dans un collège français. Je frémis d'enthousiasme, j'aime avec passion le renouveau de la musique italienne. Je respecte, j'étudie Huidobro et Unamuno. Les ÉtatsUnis m'habitent comme si eux étaient ma patrie. L'aventure de Gago Coutinho m'a fait être portugais. J'ai été Russe au Congrès de Genève. Allemand au Congrès de Versailles. Mais aux dernières élections brésiliennes, je me suis abstenu. " (Les citations des textes de Mário de Andrade ont été traduites du portugais du Brésil par Bernard Seignoux.) 
versels ${ }^{1}$. Il est intéressant d'observer de plus près la discussion autour du concept de patrie que Mário de Andrade développe dans cet article.

Tout d'abord, le titre annonce un effort de définition du concept de patrie, qui nous rapproche du titre de Renan. Le lecteur actuel doit se garder de tout a priori en ce qui concerne le recours à une terminologie très idéologiquement marquée aujourd'hui (patrie, race), mais qui était d'usage courant à l'époque. L'article présente une vision dialectique soulignant à la fois les constructions individuelles et subjectives du concept ainsi que ses implications sociales, comme l'a clairement exprimé Telê Porto Ancona Lopez. C'est ce que l'on peut lire dès l'ouverture du texte :

Tôda a gente tem a intuição do que seja pátria. Mas essa intuição difere dum para outro. Cada um constrói a sua noção conforme a sua idade, sua educaçáo, seu estado social ${ }^{2}$.

[...]

Cada qual reflete no espelho da pátria sua própria personalidade. Os orgulhosos vêem-na grande. Os vaidosos : perfeita. Os invejosos : suprema. Na verdade, para a imensa maioria dos homens, pátria é uma ilusão ${ }^{3}$.

Cette conception relativise le concept de patrie par le caractère subjectif que l'on retrouve également dans la formulation de Renan sur le concept de nation, selon laquelle " une nation est une âme, un principe spirituel » ou encore quand il affirme qu' " il y a dans la nationalité un côté de sentiment ". Tous deux soulignent d'une façon ou d'une autre le processus de construction imaginaire de la nation. Ils n'oublient pas pour autant les conditions objectives, historiques et sociales qui la fondent.

O homem é um ser eminentemente social não há dúvida. Diferenciado nas suas características particulares,

${ }^{1}$ Telê Porto Ancona Lopez, op. cit., p. 44.

${ }^{2}$ Mário de Andrade, "Noção de Pátria ». O Fanal, Sant'Anna (?), 7 set. 1922. Album de Recortes M. de A. (R. 35) - IEB-USP. « Tout le monde a une idée de ce qu'est une patrie. Mais cette idée varie d'une personne à l'autre. Selon son âge, son éducation, son statut social, chacun s'en forge une notion différente."

${ }^{3}$ Id., ibid., " [...] Dans le miroir de la patrie, chacun projette ce qu'il est. Les orgueilleux la voient puissante. Les vaniteux : parfaite. Les envieux : suprême. En réalité, l'immense majorité des gens se fait de la patrie une illusion." 
por influências de clima, de cruzamento, de instrução, em raças e sub-raças justo é que se associe aos que lhe são mais afins, aos irmãos mais próximos, pois que é impossível conservar-se um governo único para a humanidade. Mas os governos são as vigias da felicidade e da paz dessas conglomeraçōes humanas ${ }^{1}$.

Il est intéressant de constater, à travers la lecture de ce fragment, à quel point les idées du scientisme positiviste ont façonné la pensée des intellectuels brésiliens du XIX' et du début du XX⿳亠口冋 ${ }^{c}$ siècles, même chez ceux qui, comme Mário de Andrade, s'évertuaient à les combattre. Ici et là, il est possible de repérer des éléments essentiels de ce système qui, à l'époque, constituait toujours au Brésil, le cadre de référence scientifique. Nous pensons ne pas nous tromper quand nous voyons dans la citation ci-dessus des traces d'un déterminisme qui cherche à trouver l'origine de la nation, dans la race, le climat, etc., à l'opposé de Renan pour qui ces critères ne suffisaient pas à l'expliquer. Malgré cela, nous constatons que Mário de Andrade partage avec Renan plusieurs aspects de sa pensée sur la nation, comme par exemple le fait de cerner ce concept dans un mouvement dialectique entre le particulier et l'universel :

As pátrias não são mais do que ambientes em que todos nós devemos trabalhar para esse mesmo ideal de paz e de felicidade. Os homens estão reunidos em agrupamentos diversos que constituem as pátrias; mas não devem perder de vista o princípio único e o fim único que os desparticulariza e os reúne debaixo do coletivo Humanidade, para a mesma tarefa de regeneraçáo que vai do berço ao túmulo ${ }^{2}$.

\footnotetext{
${ }^{1}$ Id., ibid. "L'homme est sans aucun doute un être éminemment social. Cependant comme l'influence du climat, l'empreinte des métissages, les divers niveaux d'instruction le différencient en races et sous-races et comme, de plus, il paraît impossible de constituer un gouvernement unique et durable de l'humanité, il est juste qu'il s'associe avec ceux qui lui sont semblables, ses frères les plus proches. Il incombe alors aux divers gouvernements de veiller au bonheur et à la paix de ces regroupements humains. "

${ }^{2}$ Id., ibid. "Les patries ne sont rien d'autres que des milieux au sein desquels nous nous devons d'œuvrer pour un même idéal de bonheur et de paix. Les hommes se regroupent en diverses sociétés constituant des patries; cependant, ils ne doivent pas perdre de vue le principe unique et la fin unique qui, sous le collectif Humanité, les obligent tous, également et entre frères, du berceau à la tombe, à une même tâche de régénération. ”
} 
Une des originalités de l'œuvre de Mário de Andrade réside dans cette formulation dialectique du problème de l'identité nationale, sans qu'ily ait opposition entre les pôles du particulier et del'universel. Il s'agit des mêmes convictions affichées par Renan, formulées dans des termes qui reprennent presque mot pour mot des fragments du texte du philosophe français : les diversités des nations ne doivent pas les opposer mais les réunir dans un but unique qui est celui de contribuer à la construction idéale de l'Humanité. Il y a tout un discours pacifiste, qui au-delà de l'humanisme d'origine chrétienne que les deux écrivains partagent, peut également être justifié, chez Renan, par l'expérience récente de la guerre entre la France et la Prusse; chez Mário de Andrade, par celle de la première guerre mondiale. N'oublions pas que le premier recueil de poèmes publié en 1917 par l'écrivain brésilien s'intitule Há uma gota de sangue em cada poema, dans une claire allusion au contexte de la première guerre mondiale :

[...] E a genuína noção de pátria foi esquecida para se tornar em uns : instinto de defesa; em outros : princípio de conquista.

Será impossível voltar-se a critério exato e ideal ?

Pátria hoje, é uma conta de somar: Riqueza, mais Exército, mais Marinha'.

Dans le dernier paragraphe de "Noção de Pátria ", Mário de Andrade critique le manque de conscience morale de son temps et réaffirme l'idéal de liberté des nations qui va de pair avec leur caractère universel comme condition pour la paix et le progrès :

$\hat{E}$ a soma das vaidades e ignorâncias que nos conduziram às diversas e erradíssimas noçōes de pátria que hoje pululam na terra. Quando os governos forem respeitados pelo que são; quando as pátrias livres, sem domínio nem protetorados, sejam elas civilizadas ou selvagens (pois que é um erro pensar-se que a civilização traz felicidade) forem departamentos independentes dos Estados Universais; quando os

\footnotetext{
${ }^{1}$ Id., ibid. « Et la vraie notion de patrie a été oubliée au profit d'un instinct de défense pour les uns et pour d'autres d'un principe de conquête.

Est-il donc impossible d'en revenir à un critère exact et idéal?

Aujourd'hui, la patrie c'est une addition : Richesse, plus Armée, plus Marine. "
} 
homens alimentarem uma única generalizada e real noção do que seja uma pátria : será possível um intenso período de paz e esse verdadeiro progresso, até hoje inatingido, de todos os homens se considerarem irmãos.

E é preciso que seja assim '.

À côté de cet idéal utopique fondé sur un humanisme chrétien, il faut souligner la mise en question de la civilisation comme seul chemin capable d'assurer la dignité et le bonheur de l'homme. Dans le dernier paragraphe du texte cité ci-dessus, l'écrivain moderniste s'éloigne d'une conception de progrès positiviste et linéaire qui irait dans le sens de reproduire le parcours des grandes nations européennes occidentales, pour s'ouvrir à d'autres formes d'organisation sociale. Désir d'affirmer la complexité de l'homme et sa liberté de choix. Ce respect de l'altérité est une constante dans la vie de Mário de Andrade. Cet homme urbain, qui part en apprenti à la découverte du Nordeste du Brésil et de l'Amazonie, est celui qui créera le personnage de Macunaíma ${ }^{2}$, tiraillé entre la forêt et la ville, la magie et la raison, le jeu et le travail, pour nous parler des dimensions complexes de l'être humain et de la multiplicité de ses productions culturelles, riches, diverses et devant toutes trouver leur place dans le concert de l'humanité.

Les réflexions théoriques sur la nation chez Mário de Andrade, inaugurées dans cet article de 1922, sont loin d'être réductrices, elles supposent un dialogue interculturel. Le chef de file du Modernisme brésilien adopte une perspective dialectique pour aborder le nationa-

\footnotetext{
'Id., ibid. "C'est un cumul de nos vanités et de nos ignorances qui nous a conduits aux diverses notions de patrie, toutes aussi fausses les unes que les autres, telles qu'elles pullulent aujourd'hui sur la terre. Quand les gouvernements seront respectés pour ce qu'ils sont; quand - libres, sans impérialisme, hors protectorats, civilisées ou sauvages (imaginer que civilisation égale bonheur est une idiotie) - les patries ne seront plus que des divisions indépendantes dans le cadre d'États Universels; quand les hommes auront à l'esprit une seule, générale et bien réelle notion de ce qu'est une patrie : nous connaitrons une ère durable de paix et nous verrons ce vrai progrès, à ce jour jamais atteint, des hommes se considérant comme des frères.

Il faut qu'il en soit ainsi."

${ }^{2}$ La problématique identitaire est au cœur de son roman Macunaima (1928). Je renvoie à l'édition critique française: Andrade, Mário, Macounaïma, le héros sans aucun caractère, éd. critique française/Pierre Rivas (coord.), Paris, Stock-Unesco, 1996.
} 
lisme, qu'il envisage selon une idée de double appartenance : l'homme moderne est rattaché à sa culture particulière mais, en même temps, il appartient à un monde qui dépasse les frontières nationales. La modernité de Mário de Andrade réside dans le fait de comprendre que la problématique de l'identité nationale doit être envisagée dans la perspective de l'interdépendance culturelle. De ce fait, la connaissance approfondie de la réalité brésilienne (" Ponde os lábios na terra! Ponde os olhos na terra'!) est une voie qui conduit à l'universel. C'est ce qu'il nous donne à lire dans ce long poème qui clôt le recueil Paulicéia Desvairada, "As enfibraturas do Ipiranga ", poème qui dramatise le conflit entre l'ordre conservateur de la société et le projet moderniste représenté par la voix des "Juvenilidades Auriverdes":

Nós somos as Juvenidades Auriverdes!

As forças vivas do torrão natal,

$[\ldots]$

Todos para a fraterna música do Universal ${ }^{2}$ !

Os tumultos da luz!... As liçóes dos maiores!...

E a integralização da vida no Universal!

As estradas correndo todas para o mesmo final!...

E a pátria simples, una, inatingivelmente

Partindo para a celebração do Universal ${ }^{3}$ !

Mário de Andrade n'a pas peur du croisement des cultures, car il croit à l'intuition culturelle du peuple brésilien, capable de phagocyter des éléments étrangers sélectionnés, dans un processus d'assimilation et de réélaboration ${ }^{4}$. Deux ans avant le Manifeste Anthropophage

\footnotetext{
${ }^{1}$ Mário de Andradc, " $\Lambda$ s cnfibraturas do Ipiranga ", Paulicéia desvairada, Poesias completas, Belo Horizonte, Rio de Janeiro, Vila Rica, 1993, p. 113.

${ }^{2}$ Id., Ibid., p. 105. « Nous sommes les Jeunesses Vert et Or!

Les forces vives de la terre natale,

[...]

Unis dans la musique fraternelle de l'Universel! ”

${ }^{3}$ Id., Ibid., p. 109. "Tumultes de la lumière! Leçons de nos aînés!

Voilà comment semer de la vie dans l'Universel!

Toutes les routes menant à une même destinée!...

Et voilà la patrie, simple, une, irréductiblement

En marche pour la célébration de l'Universel!"

${ }^{4} J$ e renvoie à son article « Música Brasileira ", publié dans $A$ Manhä, São Paulo, 24-03-1926.

Cité par Telê Porto Ancona Lopez, op. cit., p. 213.
} 
d'Oswald de Andrade (1928), Mário de Andrade met en évidence l'appropriation anthropophage des éléments étrangers par la culture brésilienne. L'œuvre de cet écrivain ne fait que confirmer l'orientation centrale de son article " Noção de Pátria " qu'il écrit dans le sillage de la pensée de Renan : le nationalisme ne s'oppose pas au cosmopolitisme, mais en est au contraire une composante essentielle.

Rita Olivieri-Godet Université Rennes II-Haute-Bretagne 


\section{Annexe \\ Noção de Pátria}

Toda a gente tem a intuição do que seja uma pátria. Mas essa intuição difere dum para outro. Cada um a constrói conforme sua idade, sua educação, seu estado social.

Se os países se preocupassem mais em uniformizar essa noção, por meio do ensino, seria possível obviar muitas guerras, destruir muitas temeridades e covardias. Para a criança, a pátria é o melhor país do mundo. Para o moço pátria são os ódios raciais. Para o adulto ela é o pior país do mundo. Para o velho é o cantinho em que apanha sol. Nos países fortes a idéia de pátria associa-se às idéias de hegemonia e de conquista. Nos fracos ela se associa às idéias de inveja e rivalidade.

Há exceçōes, sem dúvida; mas raríssimas. Os instruídos alargam geralmente em demasia a noção de pátria. Chegam mesmo a perdê-la. Os ignorantes diminuem-na ao lugar em que nasceram; e vão mesmo às vezes ao ponto extremo de verem nela unicamente $o$ lar. Para o industrial pátria é sua fábrica. Para o operário é o aumento do salário com a diminuição do trabalho. Os fortes acreditam-na forte. Os doentes : inerme. Cada qual reflete no espelho da pátria sua própria personalidade. Os orgulhosos vêem-na grande. Os vaidosos : perfeita. Os invejosos : suprema. $\mathrm{Na}$ verdade para a imensa maioria dos homens pátria é uma ilusão.

Ninguém raciocina que as pátrias se fizeram pouco a pouco e, principalmente, foram criadas depois de criado o universo e o homem. Homem e Universo são criações de Deus. As pátrias são criações humanas. $\mathrm{O}$ castigo que nos assola a inteligência, trazendo as invejas, os orgulhos, os imperialismos, as conquistas, as guerras, deriva de em nossa ignorância precipitada, colocarmos a pátria acima do Universo e da Humanidade, e mesmo acima de Deus. Erro gravíssimo - causa mortis do progresso e da paz.

O homem é um ser eminentemente social, não há dúvida. Diferenciado nas suas características particulares, por influências de clima, de cruzamento, de instrução, em raças e sub-raças, justo é que se associe aos 
que lhe são mais afins, aos irmãos mais próximos, pois que é impossível conservar-se um governo único para a humanidade. Mas os governos são apenas vigias da felicidade e da paz dessas aglomeraçóes humanas.

As pátrias não são mais do que ambientes em que todos nós devemos trabalhar para esse mesmo ideal de paz e de felicidade. Os homens estão reunidos em agrupamentos diversos que constituem as pátrias; mas náo devem perder de vista o princípio e o fim único que os desparticulariza e os reúne debaixo do coletivo Humanidade, para a mesma tarefa de regeneração que vai do berço ao túmulo.

Mas lá nos coça o espírito o demônio daninho da vaidade. 'lrocamos o anseio de melhorar pela sanha de dominar. No fundo somos todos uns selvagens : os ingleses marítimos, os franceses elegantes, os norte-americanos milionários e os japoneses pertinazes. E a genuína noçáo de pátria foi esquecida para se tornar em uns : instinto de defesa; em outros : princípio de conquista.

Será impossível voltar-se a critério exato e ideal?

Pátria hoje, é uma conta de somar : Riqueza, mais Exército, mais Marinha.

$\mathrm{E}$ os homens se dizem infelizes!

Horroriza-os sem dúvida o estado de coisas atual. Mas as conferências universais se sucedem, Versalhes, Gênova e todas, sem que se chegue a uma conciliação, unicamente porque nenhuma pátria, pelos seus representantes, cede um passo nas prerrogativas a que se julga com direito. Enquanto isso a guerra mundial iniciada em 1914, continua não com exércitos e batalhas, mas transformada em carestia, em depauperamento, $\mathrm{cm}$ fome. Reinam a preguiça, a lascívia, a desmoralização. O número de vítimas é o mesmo.

$E$ os homens se dizem infelizes!

E infelizes somos realmente. Mas não devemos culpar a vida e chamar-lhe traiçoeira.

A culpa não é dela. É uma felicidade viver. É uma alegria lutar pela vida. A culpa é somente nossa. É a soma das vaidades e das ignorâncias que nos conduziram às diversas e erradíssimas noçóes de pátria que hoje pululam na terra. Quando os governos forem respeitados pelo que são; quando as pátrias livres, sem domínio nem 
protetorados, sejam elas civilizadas ou selvagens (pois que é um erro pensar-se que a civilização traz a felicidade) forem departamentos independentes dos estados Universais; quando os homens alimentarem uma única generalizada e real noção do que seja uma pátria : será possível um intenso período de paz e esse verdadeiro progresso, até hoje inatingido, de todos os homens se considerarem irmãos. E é preciso que seja assim.

Mário de Andrade

InMáriode Andrade, « NoçãodePátria ».OFanal,Sant’Anna(?), 7 set. 1922.

\section{LA NOTION DE PATRIE}

Tout le monde a une idée de ce qu'est une patrie. Mais cette idée varie d'une personne à l'autre. Selon son âge, son éducation, son statut social, chacun s'en forge une notion différente.

$\mathrm{Si}$, par l'éducation, les nations s'attachaient davantage à uniformiser cette notion de patrie, on pourrait éviter un grand nombre de guerres et en finir avec beaucoup d'entêtements et de lâchetés. Pour un enfant, la patrie est le meilleur pays qui soit. Pour un jeune homme, patrie et haines raciales sont tout un. Pour un adulte, la patrie est le pire d'entre tous les pays. Pour le vieillard, c'est juste un endroit tranquille où il prend le soleil. Dans les pays puissants, on associe l'idée de patrie à l'hégémonie et aux conquêtes. Les pays faibles n'y voient qu'envie et rivalités.

Il y a bien sûr des exceptions; mais elles sont rares. En général, les instruits glosent exagérément sur la notion de patrie. Ils en arrivent à ne plus savoir de quoi ils parlent. Les ignorants la réduisent à leur lieu de naissance; ils en viennent même quelquefois à la circonscrire à leur foyer. Pour l'industriel, la patrie c'est son usine. Pour l'ouvrier, c'est son augmentation de salaire et la diminution de sa charge de travail. Les forts la voient forte. Les malades : sans défenses. Dans le miroir de la patrie, chacun projette ce qu'il est. Les orgueilleux la 
voient puissante. Les vaniteux : parfaite. Les envieux : suprême. En réalité, l'immense majorité des gens se fait de la patrie une illusion.

Personne ne reconnaît que les patries se sont formées peu à peu et que leur création est bien postérieure à la création de l'univers et à celle de l'homme. L'Homme et l'Univers sont des créations de Dieu. Les patries sont des créations humaines. Le châtiment qui ravage notre intelligence et déchaîne envies, orgueils, impérialismes, conquêtes et guerres vient de ce que, dans notre ignorance hâtive, nous plaçons la patrie au-dessus de l'Univers et de l'Humanité et même au-dessus de Dieu. Lerreur est gravissime - causa mortis de tout progrès et de toute paix.

L'homme est sans aucun doute un être éminemment social. Cependant comme l'influence du climat, l'empreinte des métissages, les divers niveaux d'instruction le différencient en races et sous-races et comme, de plus, il parait impossible de constituer un gouvernement unique et durable de l'humanité, il est juste qu'il s'associe avec ceux qui lui sont semblables, ses frères les plus proches. Il incombe alors aux divers gouvernements de veiller au bonheur et à la paix de ces regroupements humains.

Les patries ne sont rien d'autres que des milieux au sein desquels nous nous devons d'œuvrer pour un même idéal de bonheur et de paix. Les hommes se regroupent en diverses sociétés constituant des patries; cependant, ils ne doivent pas perdre de vue le principe unique et la fin unique qui, sous le collectif Humanité, les obligent tous, également et entre frères, du berceau à la tombe, à une même tâche de régénération.

Mais là le mauvais démon de la vanité vient nous démanger l'esprit. On troque notre désir de progrès pour la rage de dominer. Au fond, nous sommes tous des sauvages : les Anglais sont des sauvages marins, les Français des sauvages en élégance, les Nord-Américains des sauvages millionnaires, et les Japonais des sauvages de détermination. La vraie notion de patrie a été oubliée au profit d'un instinct de défense pour les uns et d'un principe de conquête pour les autres.

Est-il donc impossible d'en revenir à un critère exact et idéal? Aujourd'hui, la patrie c'est une addition : Richesse, plus Armée, plus Marine. 
Et les hommes se plaignent de n'être pas heureux!

Il est vrai que l'état actuel des choses leur fait horreur. Cependant les conférences universelles se suivent, Versailles, Genève et d'autres encore, sans qu'on parvienne à la moindre conciliation uniquement parce qu'aucune patrie, à travers ses représentants, n'accepte de céder un seul pas des prérogatives auxquelles elle est persuadée d'avoir droit. Pendant ce temps, la guerre mondiale qui a commencé en 1914 se poursuit non pas avec des armées non pas avec des batailles mais avec la cherté des choses, la paupérisation, la faim. Triomphent la paresse, la lascivité, la démoralisation. Le nombre des victimes reste lui inchangé.

Et les hommes se plaignent de n'être pas heureux!

Or nous sommes réellement malheureux. Mais de cela, il ne faut pas accuser la vie ni la désigner comme traîtresse.

La faute ne vient pas d'elle. Vivre est un bonheur. Lutter pour vivre est une joie. La faute vient de nous. C'est un cumul de nos vanités et de nos ignorances qui nous a conduits aux diverses notions de patrie, toutes aussi fausses les unes que les autres, telles qu'elles pullulent aujourd'hui sur la terre. Quand les gouvernements seront respectés pour ce qu'ils sont; quand - libres, sans impérialisme, hors protectorats, civilisées ou sauvages (imaginer que civilisation égale bonheur est une idiotie) - les patries ne seront plus que des divisions indépendantes dans le cadre d'Etats Universels; quand les hommes auront à l'esprit une seule, générale et bien réelle notion de ce qu'est une patrie : nous connaîtrons une ère durable de paix et nous verrons ce vrai progrès, à ce jour jamais atteint, des hommes se considérant comme des frères. Il faut qu'il en soit ainsi.

Mário de Andrade

Mário de Andrade, « Noção de Pátria ». O Fanal, Sant’Anna (?), 7 set. 1922.

(Traduit du portugais du Brésil par Bernard Seignoux.) 